\title{
Maslinic acid suppresses the growth of human gastric cells by inducing apoptosis via inhibition of the interleukin-6 mediated Janus kinase/signal transducer and activator of transcription 3 signaling pathway
}

\author{
DEYOU WANG* ${ }^{*}$ SIFENG TANG* and QIWEN ZHANG \\ Department of General Surgery, Laiwu People's Hospital, Laiwu, Shandong 271100, P.R. China
}

Received September 5, 2015; Accepted January 19, 2017

DOI: $10.3892 / \mathrm{ol} .2017 .6073$

\begin{abstract}
The present study aimed to determine whether maslinic acid effectively inhibits the proliferation of MKN28 cells, and to investigate the mechanisms underlying its antitumor functions. MKN28 cell viability was evaluated using a Cell Counting Kit-8, cell proliferation was analyzed by a colony formation assay and flow cytometry was used to investigate the rate of apoptosis. Western blot analysis was performed in order to determine the differential expression levels of Janus kinase (JAK), signal transducer and activator of transcription 3 (STAT3) and apoptosis associated proteins B-cell lymphoma 2 (Bcl-2), Bcl-2 associated $\mathrm{X}$ protein $(\mathrm{Bax})$ and $\mathrm{Bcl}-2$ associated agonist of cell death (Bad). Interleukin-6 (IL-6) concentration was evaluated using ELISA. IL-6 and anti-IL- 6 antibodies were used to investigate the role of IL-6 in MKN28 cells treated with maslinic acid proliferation, and the STAT3 phosphorylation rates. The results demonstrated that maslinic acid treatment significantly reduced cell proliferation, induced apoptosis and was accompanied by a significant decrease in Bcl-2, Bax and Bad expression levels. Maslinic acid treatment also resulted in the downregulation of phosphorylated-STAT3 and JAK2, and significantly inhibited the protein expression of IL-6. Maslinic acid is able to inhibit MKN28 cell proliferation and the phosphorylation of STAT3 by downregulating the expression of IL- 6 . These results suggest that maslinic acid suppresses the growth of MKN28 cells by
\end{abstract}

Correspondence to: Professor Qiwen Zhang, Department of General Surgery, Laiwu People's Hospital, 1 Wenhuabei Road, Laiwu, Shandong 271100, P.R. China

E-mail: dsyu2008@163.com

*Contributed equally

Key words: maslinic acid, MKN28 cells, gastric cancer, interleukin-6, Janus kinase/signal transducer and activator of transcription 3 signaling pathway inducing apoptosis via its inhibition of the IL-6/JAK/STAT3 signaling cascade.

\section{Introduction}

Maslinic acid is a natural triterpene from Olea europaea L. (1), which acts as an antitumor, antibacterial (2) and anti-HIV substance (3), and exhibits antiallodynic and analgesic properties by regulating cell metabolism and immune function (4). Maslinic acid has been revealed to exert therapeutic effects on a variety of solid tumors, including in bladder, prostate, colon, esophageal, colorectal, cervical and ovarian cancer (5-8). However, the molecular mechanisms underlying the antitumor functions of maslinic acid remain elusive.

Interleukin-6 (IL-6) is a pleiotropic cytokine, which serves an important role in cell proliferation, differentiation, apoptosis and metastasis by participating in tumor pathogenesis (9-11). IL-6 may activate the Janus kinase (JAK)/signal transducer and activator of transcription 3 (STAT3) signaling pathway and the Ras/mitogen-activated protein kinase (MAPK) signaling pathway $(12,13)$. It has previously been demonstrated that STAT3 is constitutively phosphorylated in MKN28 cells, and it has been revealed that the inhibition of IL- 6 by IL- 6 receptor (R) antagonists, JAK inhibitors or the expression of a dominant-negative STAT3 mutant, can induce apoptosis in MKN28 cell lines in vitro (14-16). Therefore, it has been suggested that the IL-6/JAK/STAT3 signaling pathway provides an important antiapoptotic signal in tumor cells, and may be a promising target for the development of novel therapeutic strategies for gastric cancer. To the best of our knowledge, no previous studies have provided data investigating the effect and underlying mechanisms of maslinic acid in gastric cancer.

The present study demonstrated that maslinic acid inhibits the proliferation and induces apoptosis of MKN28 cells. These findings were associated with the downregulation of phosphorylated (p)-STAT3 protein and its upstream kinase, JAK. Inhibition of IL-6 production in MKN28 cells may account for the inhibition of STAT3 mediated by maslinic acid. Overall, the results of the present study provided evidence for the potential clinical application of maslinic acid as a novel therapeutic agent against gastric cancer. 


\section{Materials and methods}

Cell culture and reagents. The MNK28 human gastric cancer cell line was obtained from the American Type Culture Collection (Manassas, VA, USA.) and maintained in RPMI-1640 supplemented with $10 \%$ (v/v) heat inactivated fetal bovine serum (Gibco; Thermo Fisher Scientific, Inc., Waltham, MA, USA), $100 \mathrm{U} / \mathrm{ml}$ penicillin and $100 \mu \mathrm{g} / \mathrm{ml}$ streptomycin (Gibco; Thermo Fisher Scientific, Inc.) at $37^{\circ} \mathrm{C}$ in a humidified incubator with $5 \% \mathrm{CO}_{2}$.

Maslinic acid was obtained from Sigma-Aldrich (Merck Millipore, Darmstadt, Germany) and stock solution was prepared in dimethyl sulfoxide at $1 \mathrm{mM}$. Cell Counting Kit- 8 (CCK-8) was purchased from Dojindo Molecular Technologies, Inc. (Kumamoto, Japan). The bicinchoninic acid assay (BCA) kit (71285-3) was purchased from Beyotime Institute of Biotechnology (Haimen, China). Antibodies against STAT3 (cat. no. ab119352), p-STAT3 (Tyr705; cat. no. ab76315), JAK2 (cat. no. ab108596) and p-JAK2 (cat. no. ab32101) were purchased from Abcam (Cambridge, UK). B-cell lymphoma 2 (Bcl-2; cat. no. 2870), Bcl-2 associated agonist of cell death (Bad; cat. no. 9292), Bcl-2 associated X protein (Bax; cat. no. 2772 ) and $\beta$-actin (cat. no. 3700) antibodies were purchased from Cell Signaling Technology, Inc. (Danvers, MA, USA). Enhanced chemiluminescence (ECL) reagent was purchased from EMD Millipore (Billerica, MA, USA). A Human IL-6 Quantikine ELISA kit (D6050), recombinant human IL-6 protein (cat. no. 206-IL-050/CF) and human IL-6 antibody (cat. no. MAB206-100) were obtained from R\&D Systems, Inc. (Minneapolis, MN, USA).

Cytotoxicity assay. MKN28 cells were seeded into 24-well plates at a density of $1 \times 10^{4}$ cells/well and treated with various concentrations of maslinic acid $(0,0.1,1$ or $10 \mu \mathrm{M})$ at $37^{\circ} \mathrm{C}$ for $24 \mathrm{~h}$; subsequently CCK-8 reagent was added for a further 2-h incubation at $37^{\circ} \mathrm{C}$. Optical density was evaluated at $450 \mathrm{~nm}$ using a microplate reader (Bio-Rad Laboratories, Inc., Hercules, CA, USA). Cell number was determined using the trypan blue dye exclusion method (17).

Apoptosis analysis by Annexin V-propidium iodide (PI) double staining. The apoptotic rate of MNK28 cells was evaluated by flow cytometry using the Annexin V-fluorescein isothiocyanate (FITC)/PI double staining method. MNK28 cells were seeded in 6-well plates and treated with maslinic acid, as described above. Cells were trypsinized with $0.25 \%$ EDTA-free trypsin, then washed with PBS and centrifuged at $300 \mathrm{x}$ g for $3 \mathrm{~min}$, prior to incubation with $1 \mu \mathrm{g} / \mathrm{ml}$ Annexin V-FITC and $10 \mu \mathrm{g} / \mathrm{ml}$ PI for $15 \mathrm{~min}$ at room temperature in the dark. Samples were analyzed using a flow cytometer (BD Biosciences, Franklin Lakes, NJ, USA) and presented as two parameter dot-plots.

Clone formation assay. For each treatment group, $\sim 1 \times 10^{2}$ cells were seeded into each well of a 6-well plate. Following incubation with $0,0.1,1$ and $10 \mu \mathrm{M}$ of maslinic acid at $37^{\circ} \mathrm{C}$ for 12 days, the cells were washed with PBS and images of each clone were captured under a light microscope.

Western blotting. Following treatment with maslinic acid for $24 \mathrm{~h}, \mathrm{MKN} 28$ cells were collected and lysed in radioimmunoprecipitation assay lysis buffer $(50 \mathrm{mM}$ Tris- $\mathrm{HCl}$, pH 7.4, $150 \mathrm{mM} \mathrm{NaCl}, 1 \%$ Triton X-100, 0.1\% SDS, $1 \mathrm{mM}$ EDTA, $1 \mathrm{mM} \mathrm{Na}_{3} \mathrm{VO}_{4}, 1 \mathrm{mM} \mathrm{NaF}$ and a protease inhibitor cocktail). The extracts were incubated on ice for $30 \mathrm{~min}$ and supernatants were collected by centrifugation at $13,400 \mathrm{xg}$ for $10 \mathrm{~min}$ at $4^{\circ} \mathrm{C}$. Subsequently, protein concentrations were determined by BCA assay, $30 \mu \mathrm{g}$ protein were separated by electrophoresis on 10\% SDS-PAGE gel and electro-transferred onto a polyvinylidine fluoride membrane with transfer buffer (25 mM Tris, $250 \mathrm{mM}$ glycine and $20 \%$ methanol) at $100 \mathrm{~V}$ for $2 \mathrm{~h}$. The membrane was blocked in 5\% nonfat skimmed milk and probed with the corresponding primary antibodies at $4^{\circ} \mathrm{C}$ overnight, followed by incubation with horseradish peroxidase-conjugated goat-anti mouse $(1: 5,000$; cat. no., sc-2005) and mouse-anti rabbit (1:5,000; cat. no. sc-2357) secondary antibodies (Santa Cruz Biotechnology, Inc., Dallas, TX, USA). Primary antibodies included anti- $\beta$-actin $(1: 5,000)$, rabbit anti-human anti-STAT3 $(1: 1,000)$, rabbit anti-human anti-p-STAT3 (1:1,000), rabbit anti-human anti-Bad (1:1,000), rabbit anti-human anti-Bcl-2 (1:1,000), rabbit anti-human anti-Bax $(1: 1,000)$, rabbit anti-human anti-JAK2 $(1: 1,000)$ and rabbit anti-human anti-p-JAK2 (1:1,000). Protein expression was detected using an ECL system (GE Healthcare Biosciences, Pittsburgh, PA, USA). For western blotting, band density was determined with Quantity One 1-D software (Bio-Rad Laboratories, Inc.). Western blotting was performed in triplicate.

IL- 6 analysis by ELISA. The concentration of IL-6 in the cell culture supernatants was evaluated using the ELISA method. Briefly, MKN28 cells were plated in 24-well plates. Following treatment with maslinic acid for $24 \mathrm{~h}$, the supernatant was harvested at $13,400 \mathrm{xg}$ for $10 \mathrm{~min}$ at $4^{\circ} \mathrm{C}$ for analysis. Supernatants were analyzed using an IL-6 ELISA protein assay kit, according to the manufacturer's instructions. Color development was determined using a microplate reader (MK3; Thermo Fisher Scientific, Inc.) set to $450 \mathrm{~nm}$. A standard curve was plotted using data generated by evaluation of the absorbance of recombinant-IL-6 serial dilutions.

IL-6 and anti-IL-6 antibody treatment. Following serum starvation for $4 \mathrm{~h}, 10 \mu \mathrm{g} / \mathrm{ml}$ maslinic acid, $10 \mathrm{ng} / \mathrm{ml}$ recombinant IL-6 protein or $10 \mu \mathrm{g} / \mathrm{ml}$ anti-IL-6 antibody were added to the medium for $24 \mathrm{~h}$ of treatment at $37^{\circ} \mathrm{C}$. Cell viability was determined using CCK- 8 and the phosphorylation status of STAT3 was evaluated by western blot analysis as previously described.

Statistical analysis. Data are expressed as the mean \pm standard deviation of the mean of separate experiments $(n \geq 3)$. Student's t-test was performed for comparison of the means between the two groups, and one-way analysis of variance was used for analyzing the means of multiple groups. $\mathrm{P}<0.05$ was considered to indicate a statistically significant difference.

\section{Results}

Maslinic acid inhibits cell viability and proliferation and induces apoptosis in MKN28 cells. In order to investigate the inhibitory effects of maslinic acid on MKN28 cell viability 
A

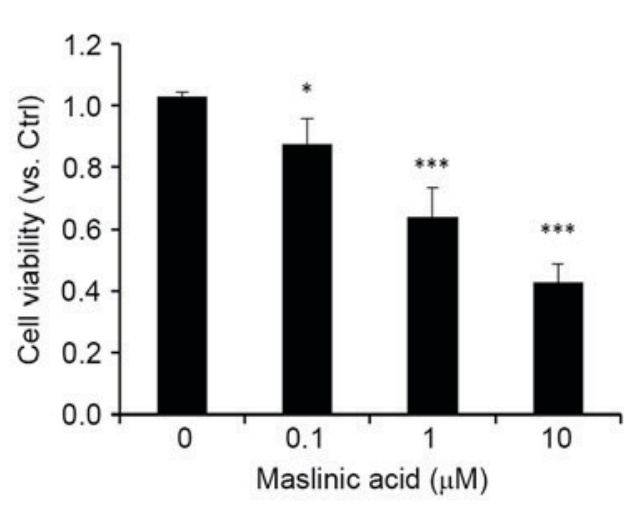

C

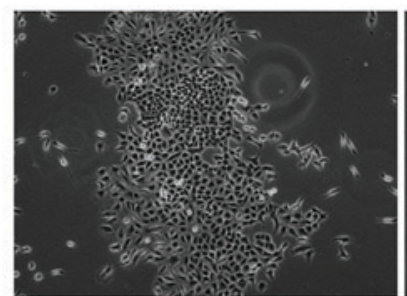

0

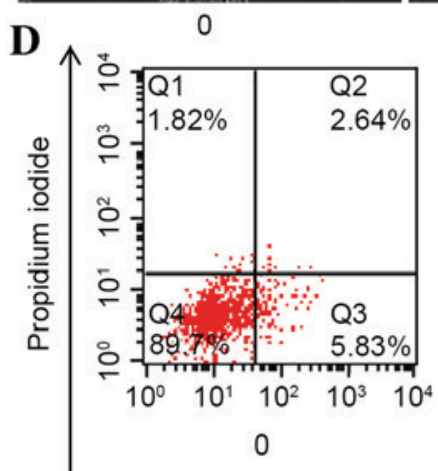

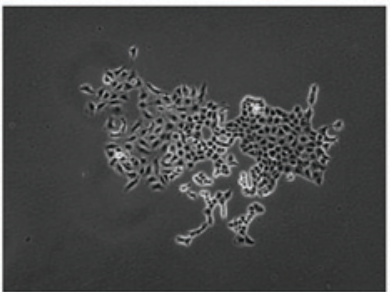

0.1

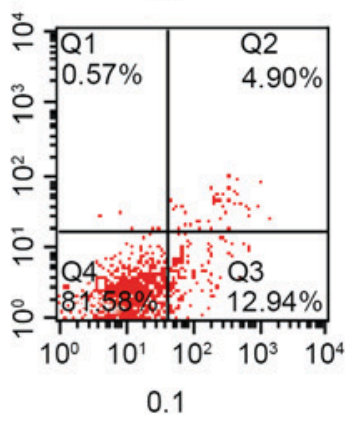

B
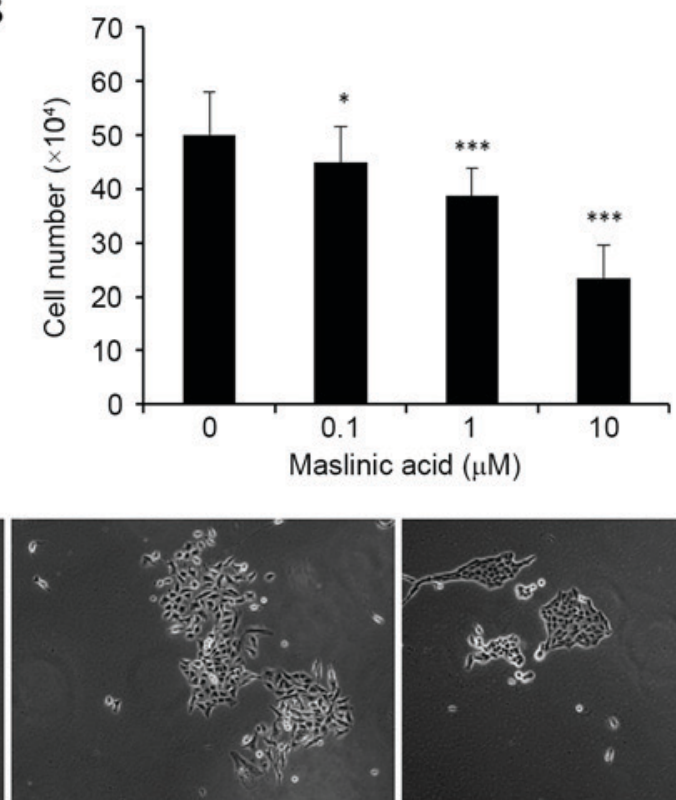

1

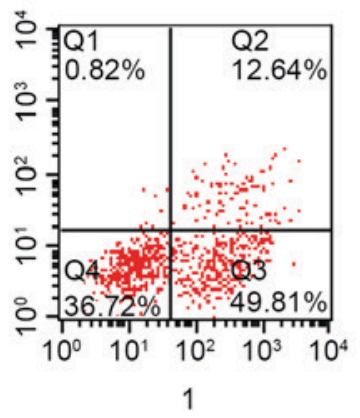

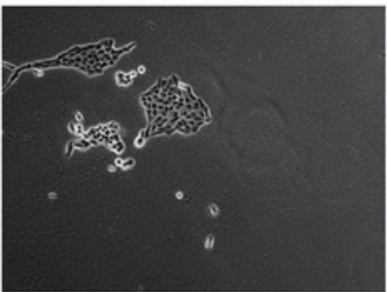

$10 \quad$ Maslinic acid $(\mu \mathrm{M})$

Annexin V/FITC

Figure 1. Maslinic acid inhibits the growth and induces apoptosis of MKN28 cells. (A) Cell viability of MKN28 cells and (B) cell number was analyzed by CCK-8 and trypan blue staining following treatment with maslinic acid at various concentrations $(0,0.1,1.0$ and $10.0 \mu \mathrm{M})$. (C) Monolayer colony formation assays suggested that maslinic acid reduced monolayer colony formation in MKN28 cells. (D) The apoptosis of MKN28 cells treated with various concentrations of maslinic acid $(0,0.1,1.0$ and $10.0 \mu \mathrm{M})$ for $24 \mathrm{~h}$ was evaluated by Annexin V-FITC/PI double staining. Results are presented as the mean \pm standard deviation of experiments conducted in triplicate. Statistical significance is indicated as ${ }^{* *} \mathrm{P}<0.01$ and ${ }^{* * *} \mathrm{P}<0.001$. Ctrl, control; CCK-8, Cell Counting Kit-8; FITC, fluorescein isothiocyanate; PI, propidium iodide.

and proliferation, the present study evaluated the cell number using trypan blue dye exclusion, and determined cell viability using the CCK-8. As presented in Fig. 1A and B, maslinic acid significantly reduced cell viability and proliferation in a dose-dependent manner with a half-maximal inhibitory concentration of $8.45 \mu \mathrm{M}, \mathrm{P}=0.032,0.00092$ and 0.000036, respectively. Colony formation assays also demonstrated a significant reduction in the size and number of colonies that received treatment with maslinic acid, $\mathrm{P}=0.047,0.00083$ and 0.00006 , respectively (Fig. 1C). The results revealed that maslinic acid has an inhibitory effect on the viability and proliferation of MKN28 cells.

Subsequently, the present study examined the apoptosis rate of MKN28 cells following treatment with maslinic acid for $24 \mathrm{~h}$ (Fig. 1D). A significantly dose-dependent increase in the percentage of early apoptotic (Annexin $\mathrm{V}^{+} / \mathrm{PI}^{-}$) and late apoptotic/necrotic (Annexin $\mathrm{V}^{+} / \mathrm{PI}^{+}$) cells was observed following culturing of MKN28 cells with maslinic acid for $24 \mathrm{~h}, \mathrm{P}=0.048,0.0082$ and 0.00074 , respectively. Totals of $5.83 \%$ for early apoptotic and $2.64 \%$ for late apoptotic/necrotic in the control group, $12.94 \%$ for early apoptotic and $4.90 \%$ for late apoptotic/necrotic in the $0.1 \mu \mathrm{M}$ maslinic acid treatment group, $49.81 \%$ for early apoptotic and $12.64 \%$ for late apoptotic/necrotic in the $1 \mu \mathrm{M}$ maslinic acid treatment group and $39.38 \%$ for early apoptotic and $38.15 \%$ for late apoptotic/necrotic in the $10 \mu \mathrm{M}$ maslinic acid treatment group, were observed. These results indicate that maslinic acid inhibits MKN28 cell viability by inducing apoptosis.

Maslinic acid inhibits the JAK/STAT3 pathway. JAK/STAT signaling is involved in oncogenesis and cancer progression by upregulation of anti-apoptotic genes (18). To explore the mechanisms underlying maslinic acid induced apoptosis, the Bcl-2 protein family expression was analyzed by western blotting. Maslinic acid treatment significantly increased the expression level of Bad compared with DMSO group, $\mathrm{P}=0.0089,0.00035$ and 0.00001 , respectively. Bcl-2/Bax expression level was significantly decreased in MKN28 cells treated with maslinic acid for $24 \mathrm{~h}$ compared with the DMSO group, $\mathrm{P}=0.0049$, 0.00088 and 0.000053 , respectively (Fig. 2A). These results 
A

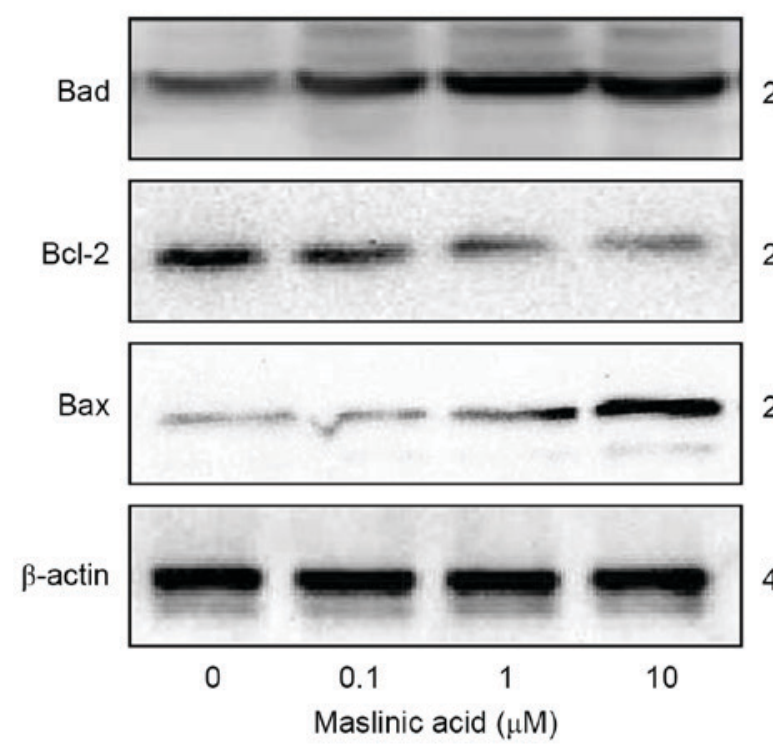

B

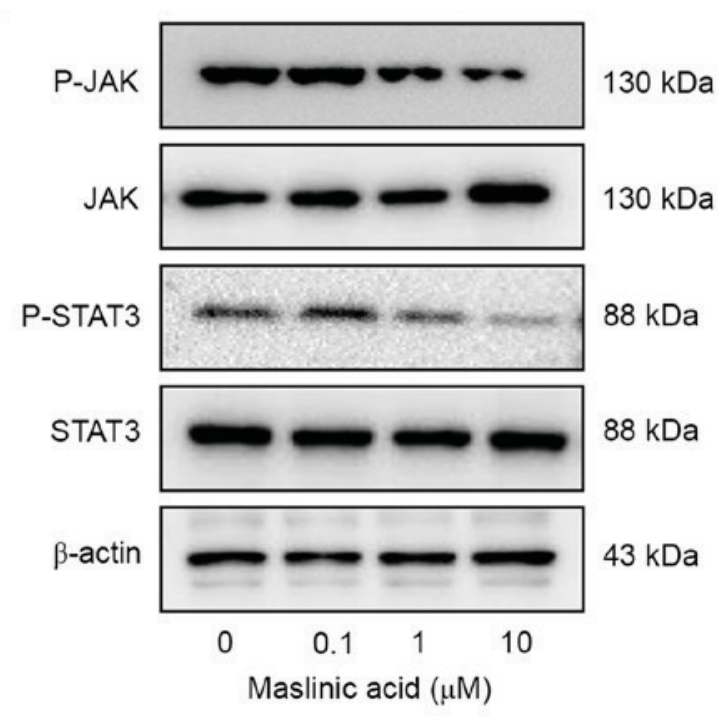

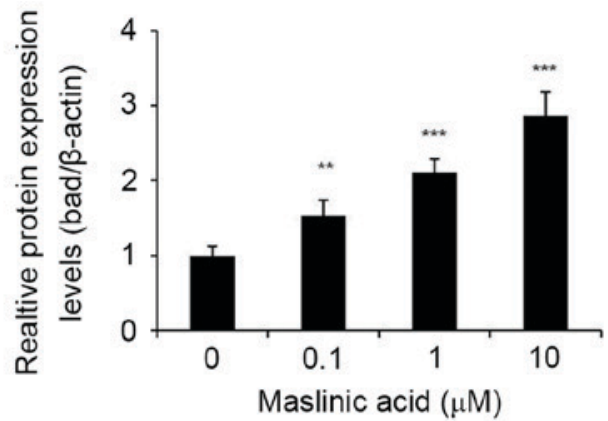

$26 \mathrm{kDa}$

$43 \mathrm{kDa}$
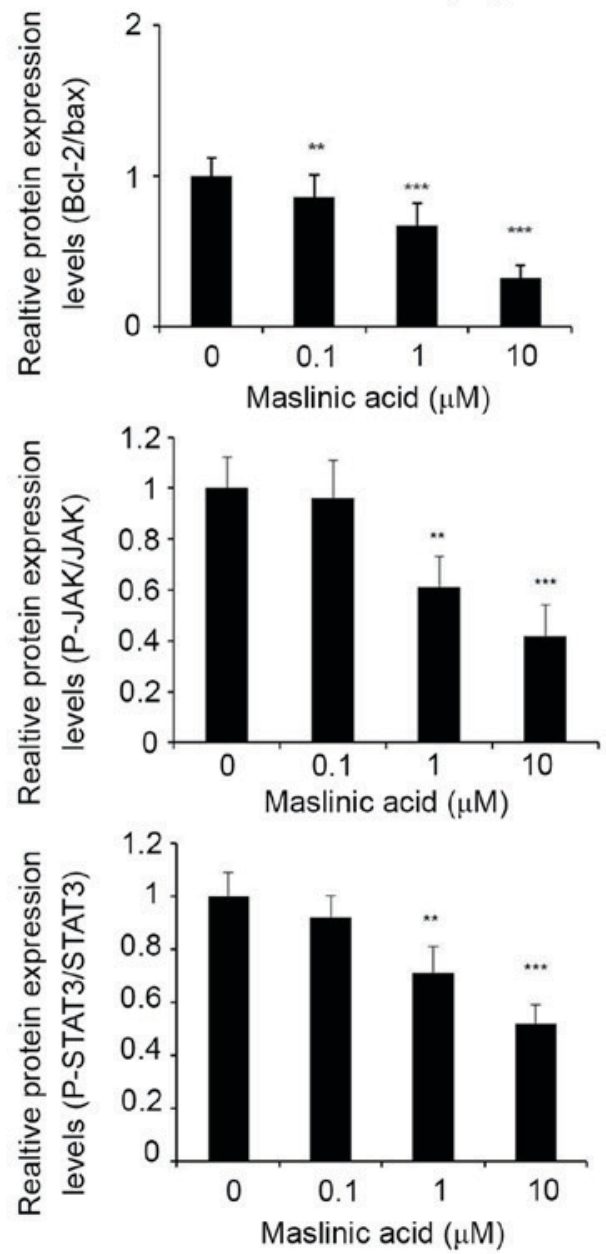

Figure 2. Maslinic acid treatment of MKN28 cells leads to an increased expression level of apoptosis associated protein and reduced JAK/STAT3 phosphorylation activity. MKN28 cells were treated with various concentrations (0, 0.1, 1.0 and $10.0 \mu \mathrm{M})$ of maslinic acid for $24 \mathrm{~h}$; subsequently, (A) the expression levels of Bcl-2 family proteins and (B) the phosphorylation of JAK/STAT3 were evaluated by western blotting. $\beta$-actin and unphosphorylated JAK or STAT3 served as a loading control. Experiments were conducted in triplicate. Statistical significance is reported as ${ }^{* *} \mathrm{P}<0.01$ and ${ }^{* * *} \mathrm{P}<0.001$. JAK, Janus kinase; STAT3, signal transducer and activator of transcription 3; Bad, Bcl-2 associated agonist of cell death; Bax, Bcl-2 associated X protein; p, phosphorylated.

indicated that the inhibition of proliferation due to maslinic acid treatment may result from significantly attenuated expression levels of Bcl-2 protein family products, including Bcl-2, Bax and Bad.

JAK/STAT3 signaling regulates gene products involved in various cellular processes including survival, proliferation and cell cycle progression (19). Western blot analysis revealed that maslinic acid treatment resulted in a marked downregulation of STAT3 phosphorylation levels without observable significant effects on the total STAT3 protein level in MKN28 cells. Inhibition of JAK 2 phosphorylation at a concentration of 1 and $10 \mu \mathrm{M}$ maslinic acid was observed, with negligible effects on total JAK2 protein levels, suggesting that the inhibition of
p-JAK2 may contribute to the inhibition of STAT3 activity induced by maslinic acid (Fig. 2B).

Maslinic acid inhibits IL-6-mediated STAT3 activation in MKN28 cells. IL-6 is one of the most prevalent cytokines that mediates its effects via the phosphorylation of STAT3 (20). As JAK/STAT3 activation is known to be involved in hematologic malignancies (21), it was imperative to determine whether maslinic acid had deleterious effects on the production of IL-6. The present study investigated the production of IL-6 in MKN28 cells using ELISA prior to and following maslinic acid treatment. A decrease of IL- 6 protein in the medium following maslinic acid treatment was revealed (Fig. 3A). 
A
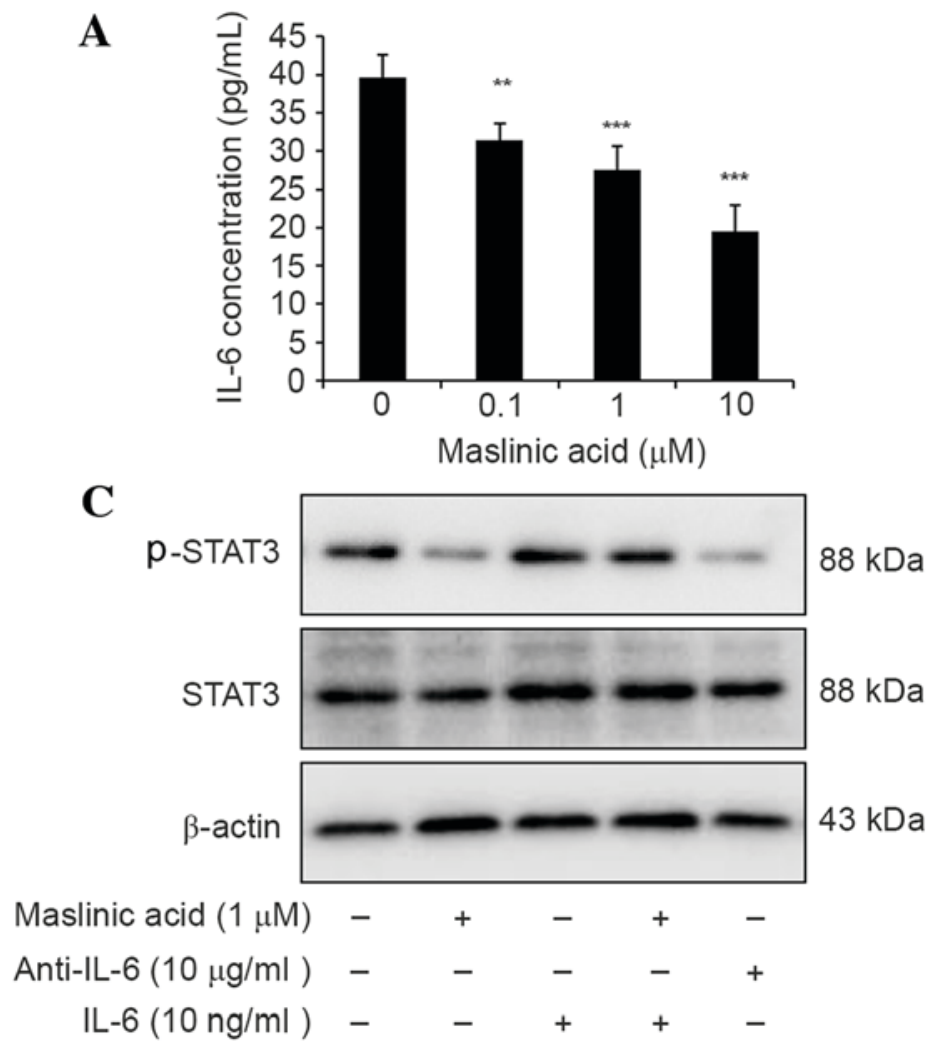

B
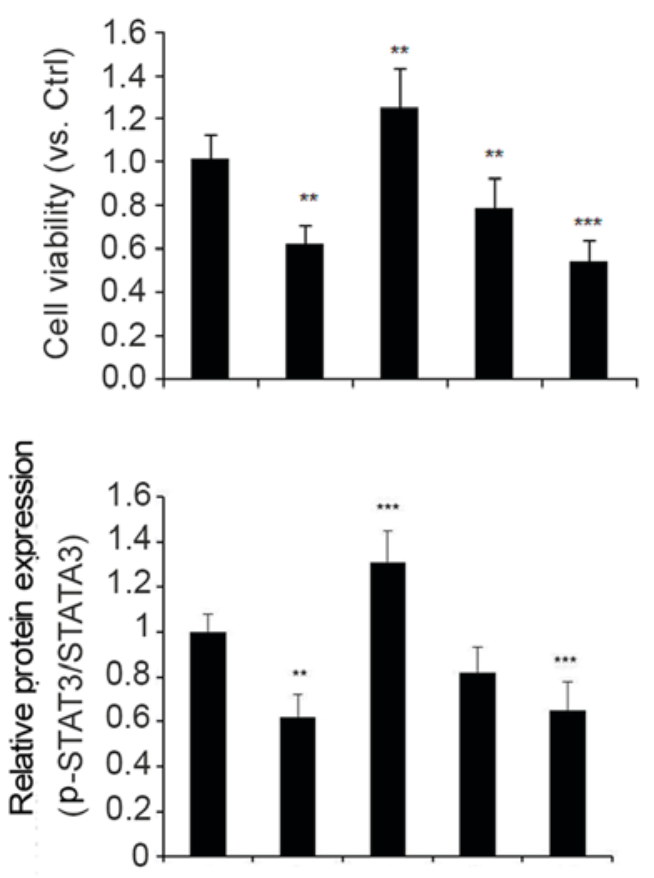

$\begin{array}{rrrrrr}\text { Maslinic acid }(1 \mu \mathrm{M}) & - & + & - & + & - \\ \text { Anti-IL-6 }(10 \mu \mathrm{g} / \mathrm{ml}) & - & - & - & - & + \\ \text { IL-6 }(10 \mathrm{ng} / \mathrm{ml}) & - & - & + & + & -\end{array}$

Figure 3. Effect of treatment with various concentrations of maslinic acid on the phosphorylation of STAT3 protein in MKN28 cells. (A) The concentration of IL-6 in the medium following treatment with maslinic acid was detected using an ELISA. (B) CCK-8 was used to analyze the viability of MNK28; cells were harvested for protein extraction and subjected to $(\mathrm{C})$ western blot analysis with an anti-p-STAT3 antibody to determine the phosphorylation status of STAT3 protein. Total STAT3 and $\beta$-actin were used as the controls. Experiments were conducted in triplicate. Statistical significance is reported as ${ }^{* *} \mathrm{P}<0.01$ and ${ }^{* * *} \mathrm{P}<0.001$. STAT3, signal transducer and activator of transcription 3; IL-6, interleukin-6; CCK-8, Cell Counting Kit-8; p, phosphorylated; ctrl, control.

Therefore, it is likely that suppression of the JAK/STAT3 signaling pathway following maslinic acid treatment may be induced by the upstream inhibition of IL- 6 expression.

Pretreatment with the anti-IL-6 antibody for $24 \mathrm{~h}$ also resulted in the inhibition of cell viability and phosphorylation of STAT3. The addition of recombinant IL- 6 to the medium resulted in an increase in cell viability and the reactivation of STAT3 phosphorylation, suggesting that IL-6 is responsible for STAT3 activation (Fig. 3B and C). Taken together, these findings suggest that maslinic acid serves an important role in the inhibition of IL-6-mediated STAT3 activation in the MKN28 gastric cancer cell line.

\section{Discussion}

Maslinic acid is a natural triterpene from Olea europaea L. (1). Accumulating evidence exists that maslinic acid may inhibit the growth of various human tumor cell lines in vitro $(1,22,23)$. In vivo studies also demonstrated that maslinic acid inhibits the growth of various types of cancer cells in mice, including the HT29 human colon-cancer cell line (24), Panc-28 pancreatic cell line, Panc-1, BxPC-3, AsPC-1 (22) and Raji B lymphoma cell line (25). Although the antitumor effects of maslinic acid have been demonstrated in vitro and in vivo for various types of cancer (22-25), little is known about its effect and underlying mechanisms in gastric cancer.

In the present study, maslinic acid was demonstrated to inhibit MKN28 cell viability in a dose-dependent manner using CCK-8, and to induce cell apoptosis as determined using flow cytometry. The western blot analysis results revelead that maslinic acid increased the protein level of Bad and inhibited the Bcl-2/Bax ratio, which indicated the cell survival or apoptosis grade. These results confirmed that maslinic acid exhibits a significant anticancer effect on MKN28 cells. Subsequently, the present study focussed on the molecular mechansims underlying the maslinic acid-mediated inhibition of MKN28 cell proliferation.

Inflammation is recognized to serve an important role in the pathogenesis of numerous types of tumors, and is a critical component of tumor progression (26). The production and release of various survival factors, including IL-6, a major mediator of inflammation, serves to block apoptosis in cells during the inflammatory process, keeping them alive in toxic environments (27). IL-6 binds to the soluble IL-6R (glycoprotein (gp)80, present either on the cell surface or in solution), which then induces dimerization of gp130 chains resulting in activation of the associated JAKs (28). JAKs phosphorylate gp130, leading to the recruitment and activation of STAT3 transcription factors, as well as other molecules (29). STAT3 is constitutively activated in various gastric cancer cells, and is often associated with cell survival, proliferation and transformation (30).

The present study revealed that maslinic acid treatment inhibits IL- 6 protein secretion and results in loss of STAT3 phosphorylation, accounting for the inhibition of the IL-6/STAT3 signaling pathway. Western blot analysis 
was used for evaluation of the expression levels of JAK2, an upstream protein tyrosine kinase, which serves an important role in STAT3 homo-dimer formation and activation (31). The results demonstrated that maslinic acid treatment of MKN28 cells results in a significantly diminished expression level of p-JAK2 protein. Taken together, these results suggest that the inactivation of upstream p-JAK2 is involved in the inhibition of the IL-6-JAK/STAT3 signaling pathway in MKN28 cells.

A number of previous studies have indicated that constitutive activation of STAT3 is mediated via autocrine/paracrine stimulation by cytokines, including the IL-6 family of cytokines, involved in hematopoietic development (32-35). In order to further explore the mechanisms underlying inhibition of IL-6 induced by maslinic acid, the present study used an anti-IL-6 antibody to block the endogenous IL-6 or recombinant IL-6 protein, in order to restore STAT3 phosphorylation in MKN28 cells, thus suggesting that IL-6 was responsible for STAT3 activation. The results confirmed that the overexpression of IL-6 promoted tumor growth and STAT3 phosphorylation, and the inhibition of IL- 6 production may decrease cell proliferation and phosphorylation of STAT3. In addition, maslinic acid may decrease IL- 6 protein levels in the culture medium of MKN28 cells. Thus, the anticancer properties of maslinic acid may result from its inhibition of IL- 6 expression and subsequent inhibition of downstream JAK2/STAT3 signaling.

To the best of our knowledge, no previous studies have investigated the effect of maslinic acid on the IL-6-JAK/STAT3 signaling cascade in gastric cancer cells. The results of the present study have demonstrated for the first time that the underlying mechanism of maslinic acid anti-gastric tumor activity is the inhibition of IL-6 expression and subsequent downregulation of the JAK/STAT3 signaling pathway. It was revealed that maslinic acid inhibited the generation and secretion of IL-6 in MKN28 cells, induced JAK and STAT3 phosphorylation and downregulated the expression levels of STAT3-mediated proteins involved in apoptosis and proliferation (Bad, Bcl-2 and Bax). However, further investigation is required in order to elucidate the direct molecular mechanisms underlying the maslinic acid inhibition of IL-6. It is possible that maslinic acid may be useful as a therapeutic treatment for gastric cancer.

\section{References}

1. Reyes-Zurita FJ, Rufino-Palomares EE, Lupiáñez JA and Cascante M: Maslinic acid, a natural triterpene from Olea europaea L., induces apoptosis in HT29 human colon-cancer cells via the mitochondrial apoptotic pathway. Cancer Lett 273: 44-54, 2009.

2. Pavel IZ, Danciu C, Oprean C, Dehelean CA, Muntean D, Csuk R and Muntean DM: In vitro evaluation of the antimicrobial ability and cytotoxicity on two melanoma cell lines of a benzylamide derivative of maslinic acid. Anal Cell Pathol (Amst) 2016: 2787623,2016

3. Parra A, Rivas F, Lopez PE, Garcia-Granados A, Martinez A, Albericio F, Marquez N and Muñoz E: Solution- and solid-phase synthesis and anti-HIV activity of maslinic acid derivatives containing amino acids and peptides. Bioorg Med Chem 17: $1139-1145,2009$.

4. Nieto FR, Cobos EJ, Entrena JM, Parra A, García-Granados A and Baeyens JM: Antiallodynic and analgesic effects of maslinic acid, a pentacyclic triterpenoid from Olea europaea. J Nat Prod 76: 737-740, 2013.

5. Zhang S, Ding D, Zhang X, Shan L and Liu Z: Maslinic acid induced apoptosis in bladder cancer cells through activating p38 MAPK signaling pathway. Mol Cell Biochem 392: 281-287, 2014.
6. Park SY, Nho CW, Kwon DY, Kang YH, Lee KW and Park JH: Maslinic acid inhibits the metastatic capacity of DU145 human prostate cancer cells: Possible mediation via hypoxia-inducible factor-1 $\alpha$ signalling. Br J Nutr 109: 210-222, 2013.

7. Rufino-Palomares EE, Reyes-Zurita FJ, García-Salguero L, Mokhtari K, Medina PP, Lupiáñez JA and Peragón J: Maslinic acid, a triterpenic anti-tumoural agent, interferes with cytoskeleton protein expression in HT29 human colon-cancer cells. J Proteomics 83: 15-25, 2013.

8. Reyes-Zurita FJ, Pachón-Peña G, Lizárraga D, Rufino-Palomares EE, Cascante M and Lupiáñez JA: The natural triterpene maslinic acid induces apoptosis in HT29 colon cancer cells by a JNK-p53-dependent mechanism. BMC Cancer 11: 154, 2011.

9. Burger R: Impact of interleukin-6 in hematological malignancies. Transfus Med Hemother 40: 336-343, 2013.

10. Reynaud D, Pietras E, Barry-Holson K, Mir A, Binnewies M, Jeanne M, Sala-Torra O, Radich JP and Passegué E: IL-6 controls leukemic multipotent progenitor cell fate and contributes to chronic myelogenous leukemia development. Cancer Cell 20: 661-673, 2011.

11. Hirano T, Ishihara K and Hibi M: Roles of STAT3 in mediating the cell growth, differentiation and survival signals relayed through the IL-6 family of cytokine receptors. Oncogene 19: 2548-2556, 2000.

12. Heinrich P, Behrmann I, Müller-Newen G, Schaper F and Graeve L: Interleukin-6-type cytokine signalling through the gp130/Jak/STAT pathway. Biochem J 334: 297-314, 1998.

13. Ogata A, Chauhan D, Teoh G, Treon SP, Urashima M, Schlossman RL and Anderson KC: IL-6 triggers cell growth via the Ras-dependent mitogen-activated protein kinase cascade. J Immunol 159: 2212-2221, 1997.

14. Huang W, Yu LF, Zhong J, Wu W, Zhu JY, Jiang FX and Wu YL: Stat3 is involved in angiotensin II-induced expression of MMP2 in gastric cancer cells. Dig Dis Sci 54: 2056-2062, 2009.

15. Ding SZ, Cho $\mathrm{CH}$ and Lam SK: Regulation of interleukin 6 production in a human gastric epithelial cell line MKN-28. Cytokine 12: 1129-1135, 2000.

16. To KF, Chan MW, Leung WK, Ng EK, Yu J, Bai AH, Lo AW, Chu SH, Tong JH, Lo KW, et al: Constitutional activation of IL-6-mediated JAK/STAT pathway through hypermethylation of SOCS-1 in human gastric cancer cell line. Br J Cancer 91: 1335-1341, 2004.

17. Strober W: Trypan blue exclusion test of cell viability. Curr Protoc Immunol Appendix 3: Appendix 3B, 2001.

18. Catlett-Falcone R, Landowski TH, Oshiro MM, Turkson J, Levitzki A, Savino R, Ciliberto G, Moscinski L, FernándezLuna JL, Nuñez G, et al: Constitutive activation of Stat 3 signaling confers resistance to apoptosis in human U266 myeloma cells. Immunity 10: 105-115, 1999.

19. Shain KH, Yarde DN, Meads MB, Huang M, Jove R, Hazlehurst LA and Dalton WS: Betal integrin adhesion enhances IL-6-mediated STAT3 signaling in myeloma cells: Implications for microenvironment influence on tumor survival and proliferation. Cancer Res 69: 1009-1015, 2009.

20. Zhong Z, Wen Z and Darnell JE Jr: Stat3: A STAT family member activated by tyrosine phosphorylation in response to epidermal growth factor and interleukin-6. Science 264: 95-98, 1994.

21. Al Zaid Siddiquee K and Turkson J: STAT3 as a target for inducing apoptosis in solid and hematological tumors. Cell Res 18: 254-267, 2008.

22. Li C, Yang Z, Zhai C, Qiu W, Li D, Yi Z, Wang L, Tang J, Qian M, Luo $\mathrm{J}$ and Liu M: Maslinic acid potentiates the anti-tumor activity of tumor necrosis factor alpha by inhibiting NF-kappaB signaling pathway. Mol Cancer 9: 73, 2010.

23. Wu DM, Zhao D, Li DZ, Xu DY, Chu WF and Wang XF: Maslinic acid induces apoptosis in salivary gland adenoid cystic carcinoma cells by $\mathrm{Ca}^{2+}$-evoked p38 signaling pathway. Naunyn Schmiedebergs Arch Pharmacol 383: 321-330, 2011.

24. Reyes-Zurita FJ, Rufino-Palomares EE, Lupiáñez JA and Cascante M: Maslinic acid, a natural triterpene from Olea europaea L., induces apoptosis in HT29 human colon-cancer cells via the mitochondrial apoptotic pathway. Cancer Lett 273: 44-54, 2009.

25. Hsum YW, Yew WT, Hong PL, Soo KK, Hoon LS, Chieng YC and Mooi LY: Cancer chemopreventive activity of maslinic acid: Suppression of COX-2 expression and inhibition of NF- $\kappa B$ and AP-1 activation in raji cells. Planta Med 77: 152-157, 2011.

26. Coussens LM and Werb Z: Inflammation and cancer. Nature 420: $860-867,2002$. 
27. Hodge DR, Hurt EM and Farrar WL: The role of IL-6 and STAT3 in inflammation and cancer. Eur J Cancer 41: 2502-2512, 2005.

28. Murakami M, Hibi M, Nakagawa N, Nakagawa T, Yasukawa K, Yamanishi K, Taga T and Kishimoto T: IL-6-induced homodimerization of gp130 and associated activation of a tyrosine kinase. Science 260: 1808-1810, 1993.

29. Heinrich PC, Behrmann I, Müller-Newen G, Schaper F and Graeve L: Interleukin-6-type cytokine signalling through the gp130/Jak/STAT pathway. Biochem J 334: 297-314, 1998.

30. Kanda N, Seno H, Konda Y, Marusawa H, Kanai M, Nakajima T, Kawashima T, Nanakin A, Sawabu T, Uenoyama Y, et al: STAT3 is constitutively activated and supports cell survival in association with survivin expression in gastric cancer cells. Oncogene 23: 4921-4929, 2004.

31. Endo TA, Masuhara M, Yokouchi M, Suzuki R, Sakamoto H, Mitsui K, Matsumoto A, Tanimura S, Ohtsubo M, Misawa H, et al: A new protein containing an $\mathrm{SH} 2$ domain that inhibits JAK kinases. Nature 387: 921-924, 1997.

32. Yadav A, Kumar B, Datta J, Teknos TN and Kumar P: IL-6 promotes head and neck tumor metastasis by inducing epithelial-mesenchymal transition via the JAK-STAT3-SNAIL signaling pathway. Mol Cancer Res 9: 1658-1667, 2011.
33. Sriuranpong V, Park JI, Amornphimoltham P, Patel V, Nelkin BD and Gutkind JS: Epidermal growth factor receptor-independent constitutive activation of STAT3 in head and neck squamous cell carcinoma is mediated by the autocrine/paracrine stimulation of the interleukin 6/gp130 cytokine system. Cancer Res 63: 2948-2956, 2003.

34. Alas S and Bonavida B: Rituximab inactivates signal transducer and activation of transcription 3 (STAT3) activity in B-non-Hodgkin's lymphoma through inhibition of the interleukin 10 autocrine/paracrine loop and results in down-regulation of Bcl-2 and sensitization to cytotoxic drugs. Cancer Res 61: 5137-5144, 2001

35. Sano M, Fukuda K, Kodama H, Takahashi T, Kato T, Hakuno D, Sato T, Manabe T, Tahara S and Ogawa S: Autocrine/Paracrine secretion of IL-6 family cytokines causes angiotensin II-induced delayed STAT3 activation. Biochem Biophys Res Commun 269: 798-802, 2000. 